\title{
Chemotactic Activity of Cyclophilin A in the Skin Mucus of Yellow Catfish (Pelteobagrus fulvidraco) and Its Active Site for Chemotaxis
}

\author{
Farman Ullah Dawar ${ }^{1}$, Jiagang Tu ${ }^{1}$, Yang Xiong ${ }^{1}$, Jiangfeng Lan ${ }^{1}$, Xing Xing Dong ${ }^{1}$, \\ Xiaoling Liu ${ }^{1,2}$, Muhammad Nasir Khan Khattak ${ }^{3}$, Jie Mei ${ }^{1,2, *}$ and Li Lin ${ }^{1,2, *}$ \\ 1 College of Fisheries, Huazhong Agricultural University, Wuhan 430070, China; \\ farmandawar2012@yahoo.com (F.U.D.); tujiagang@mail.hzau.edu.cn (J.T.); 13697134024@163.com (Y.X.); \\ lanjiangfeng@mail.hzau.edu.cn (J.L.); dongxingxinghg@163.com (X.X.D.); liuxl@mail.hzau.edu.cn (X.L.); \\ 2 Freshwater Aquaculture Collaborative Innovation Center of Hubei Province, Wuhan 430070, China \\ 3 Department of Zoology, Hazara University, Mansehra 21300, Pakistan; mnasir43663@googlemail.com \\ * Correspondence: jmei@mail.hzau.edu.cn (J.M.); linli@mail.hzau.edu.cn (L.L.); Tel.: +86-139-8617-9406 (J.M.); \\ +86-27-8728-2113 (L.L.)
}

Academic Editor: Helmut Segner

Received: 17 July 2016; Accepted: 23 August 2016; Published: 29 August 2016

\begin{abstract}
Fish skin mucus is a dynamic barrier for invading pathogens with a variety of anti-microbial enzymes, including cyclophilin A (CypA), a multi-functional protein with peptidyl-prolyl cis/trans isomerase (PPIase) activity. Beside various other immunological functions, CypA induces leucocytes migration in vitro in teleost. In the current study, we have discovered several novel immune-relevant proteins in yellow catfish skin mucus by mass spectrometry (MS). The CypA present among them was further detected by Western blot. Moreover, the CypA present in the skin mucus displayed strong chemotactic activity for yellow catfish leucocytes. Interestingly, asparagine (like arginine in mammals) at position 69 was the critical site in yellow catfish CypA involved in leucocyte attraction. These novel efforts do not only highlight the enzymatic texture of skin mucus, but signify CypA to be targeted for anti-inflammatory therapeutics.
\end{abstract}

Keywords: yellow catfish; skin mucus; cyclophilin A; chemotaxis; immune response

\section{Introduction}

The fish mucosal surface, like skin, is regularly exposed to pathogens and secretes adherent mucus that covers its epithelial layer $[1,2]$. Fish skin mucus is a natural, semipermeable, biochemically-diverse and dynamic barrier that is important for maintaining normal fish physiology and conferring defense against microbial infections [3,4]. Skin mucus characterizations from different fish species revealed several proteases, including serine and metalloproteases with strong antimicrobial capabilities [5-7]. Studies reported several innate immune factors, such as glycoproteins, lysozyme, antimicrobial peptides and immunoglobulins in fish skin mucus [8-10]. Others reported that fish skin mucus contains peroxidase, alkaline phosphatase, esterases, proteases, antiproteases [11], galectin-1, mannan binding lectin (MBL), serpins, cystatin B, FK-506 binding protein, proteasome subunits ( $\alpha-3$ and -7 ), ubiquitin, g-type lysozyme and CypA, as well [12].

CypA is an immunophilin with peptidyl-prolyl cis/trans isomerase (PPIase) activity and acts as a cellular receptor for immunosuppressive drug cyclosporine A (CsA). It regulates numerous cellular functions being a cytosolic protein; however, it is also considered as a critical immune mediator with strong anti-viral activity [13]. Furthermore, it is also involved in protein folding and trafficking [14], gene regulation [15], genome degradation [16] and cell signaling pathways, such as interleukin-2 tyrosine kinase (Itk) [17]. Extracellular CypA works against inflammatory stimuli, such as infection, 
oxidative stress and hypoxia [18-20]. Its association with different diseases, likes sepsis, asthma, periodontitis, aging, cardiovascular diseases, neurodegeneration, cancer and rheumatoid arthritis (RA), is widely evidenced [14,21]. CypA involvement is essential in the progression and inhibition of several viral infections and is widely targeted for controlling viral diseases [13]. CypA also functions against lipopolysaccharides (LPS) and bacterial challenge [22-24].

In addition to various physiological and pathological functions $[25,26]$, extracellular CypA is a potent chemoattractant to induce human leucocytes migration during inflammation [27]. Cells secrete CypA in response to inflammatory stimuli and cell death [18], where it interacts with CD147, the main receptor for CypA on the cell membrane of human leucocytes, and exhibits leucocyte chemotaxis $[26,28]$. In rheumatoid arthritis (RA) patients, the abundant CypA upregulates the adhesion and invasion of neutrophils by direct binding to CD147 and subsequently destroys cartilage and bones [29]. In mouse, CypA interacts with typical chemokine (MIP-2) and increases leucocyte recruitment after acute lung inflammation [30]. In cattle, extracellular CypA was observed in tissues with inflammation and had shown a strong chemotactic activity for bovine peripheral blood cells [31]. Guo [32] demonstrated that CypA induced cell migration via CD147, which correlates with cell aggregation in Jurkat T cells. Similarly, Yeh [33] reported that channel catfish CypA has strong chemotactic activity for peritoneal macrophages. Recently, CypA was characterized from yellow catfish, with chemotactic activity for leucocytes [34]. However, its presence and function in yellow catfish skin mucus is unknown. Therefore, in the present study, first we have screened the skin mucus of yellow catfish and found defensive enzymes, including CypA. Furthermore, the CypA showed chemotactic activity for leucocytes in the skin mucus of yellow catfish. Additionally, a required critical site of yellow catfish CypA responsible for chemotaxis has also been discovered. This study does not only highlight the mucosal function of CypA, but would help to investigate this protein in the teleost immune and pathogenic processes in the future.

\section{Results}

\subsection{Mass Spectrometry and Western Blot Analysis}

The mass spectrometric analysis identified and characterized the immune-relevant proteins in the skin mucus as interferon-induced GTP-binding protein $\mathrm{Mx} 1$, vasa short form, $\beta$-enolase, recombination activating protein 1, lsm12-like protein A and CypA. These peptides have shown hits to expressed sequence tags (EST)-bases, and their theoretical molecular masses (Da) were 72,882, 70,798, 47,773, $46,987,21,644$ and 17,724 , respectively. All of the proteins are presented with their respective species and accession number to which they matched with the annotated score of 30,31,36, 28, 31 and 32, respectively (Table 1). The matching amino acid sequences, reference numbers and percent identity are shown in supplementary materials (Table S1). CypA was detected by Western blot in the skin mucus with a precise band size as that in other body tissues and is shown in Figure 1.

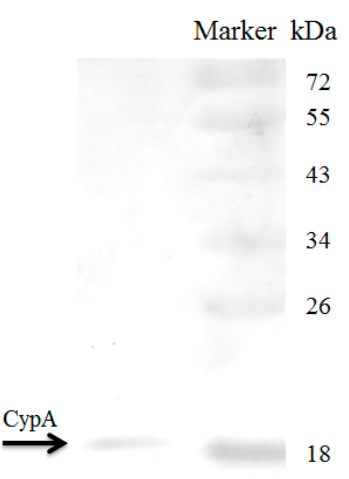

Figure 1. Result of CypA in the skin mucus detected by Western blot. Anti-CypA antibody was used to detect CypA. The CypA band is marked and equal to the precise size ( $18 \mathrm{kDa})$ of the marker. 
Table 1. Proteins putatively annotated in the skin mucus of yellow catfish using mass spectrometry. The detailed procedure used to putatively annotate the detected protein is present in the Materials and Methods section. Mucus was assessed by mass spectrometry; the identified proteins are shown with their molecular masses and the matching species with the accession number in the database.

\begin{tabular}{|c|c|c|c|c|c|}
\hline Serial No. & Protein Name & $M_{\mathrm{W}}(\mathrm{Da})$ & Score & Species & Accession No. \\
\hline 1 & Interferon-induced GTP-binding protein Mx1 & 72,882 & 30 & Ictalurus punctatus & gi 182208280 \\
\hline 2 & Vasa short form & 70,798 & 31 & Silurus meridionalis & gi | 188529679 \\
\hline 3 & $\beta$-Enolase & 47,773 & 36 & Ictalurus furcatus & gi | 308321422 \\
\hline 4 & Recombination activating protein 1 & 46,987 & 28 & Pimelodus maculatus & gil 382928308 \\
\hline 5 & lsm12-like protein A & 21,644 & 31 & Ictalurus furcatus & gil 308322011 \\
\hline 6 & Cyclophilin A & 17,724 & 32 & Ictalurus punctatus & gi | 318264336 \\
\hline
\end{tabular}

\subsection{Chemotaxis Assay of Skin Mucus}

The chemotactic activity of various concentrations of the skin mucus is shown in Figure 2. The activity was very low when the concentration of mucus was $0.001 \%$ with the chemotactic index of 1.43 , while it became significantly higher as the concentration of mucus raised to $1 \%$ and then $10 \%$ with chemotactic indexes of 3.83 and 5.35, respectively. Overall, the chemotaxis was strongly concentration-dependent as there were significant differences among the lower and higher and highest concentrations (Figure 2). However, the activity was significantly reduced after the addition of anti-CypA antibodies when compared with the negative control (rabbit serum plus skin mucus). After blocking CypA with antibodies in the mucus, the activity in the $0.001 \%$ group was 1.26 , which was decreased gradually and was 1.18 and 1.07 in the $1 \%$ and $10 \%$ mucus concentration groups. However, the activity in the negative control group (rabbit serum plus mucus) was 1.6 in $0.001 \%$, which rose to 3.9 in the $1 \%$ and 5.2 in the $10 \%$ concentration groups of skin mucus. All of these activities were significantly higher than the group treated with antibodies. This result suggests that the higher activity is due to CypA present in the mucus, as the rabbit serum has no effect on leukocyte migration (Figure 2).

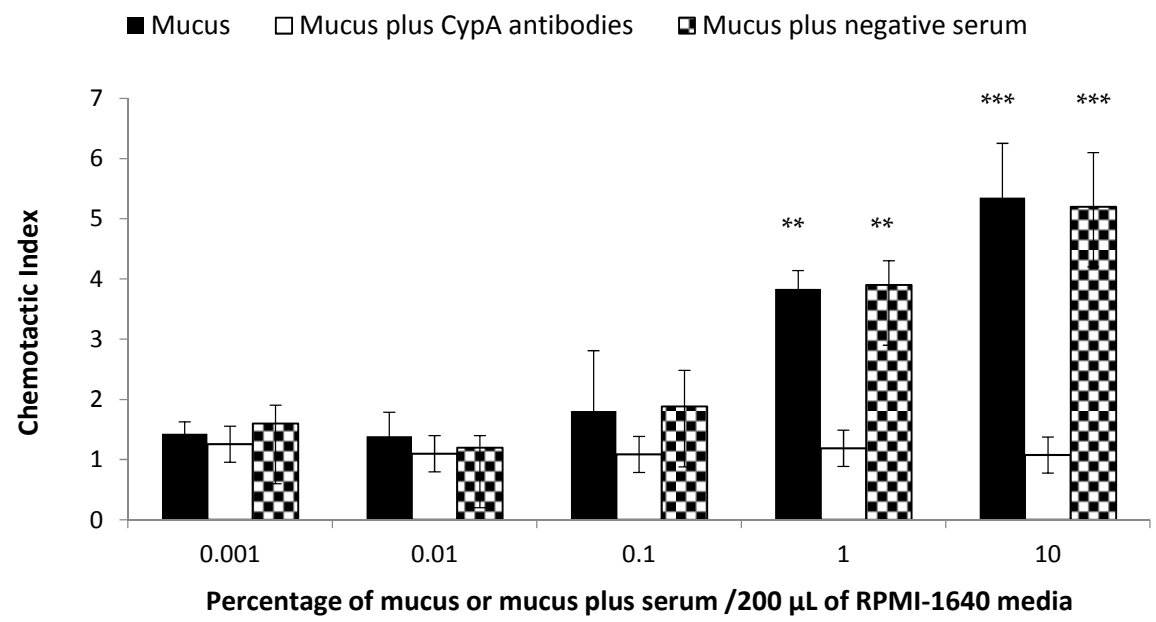

Figure 2. Comparative chemotactic activity of various concentrations of yellow catfish skin mucus. The black bar shows the chemotactic activity of various concentrations of yellow catfish skin mucus for head kidney leucocytes of yellow catfish. The white bar shows the chemotactic activity of the skin mucus when the CypA was blocked by CypA-specific antibodies. The doted bar indicates the chemotactic activity of skin mucus plus serum (negative control). The chemotactic activity is shown as the chemotactic index. Data are expressed as the means $\pm \mathrm{SD},(n=3)$ of three fish. Bars with "*** are highly significantly different $(p<0.01)$, while bars with "****" are very highly significantly different $(p<0.001)$. 


\subsection{Chemotactic Activity of Mutant CypA}

The wild-type and mutant-type CypA proteins (termed as CypA ${ }^{\mathrm{wt}}$ and $\mathrm{CypA}^{\mathrm{mt}}$ ) were purified after expression and are shown in Figure 3. Both of the GST-fused proteins have an equal size of $43 \mathrm{kDa}$, and their chemotactic activity is depicted in Figure 4 . The chemotactic index was about 3.08 in wild-type, while it was one in CypA ${ }^{\mathrm{mt}}$, which is significantly lower than wild-type. This significant lower chemotactic index in the $\mathrm{CypA}^{\mathrm{mt}}$ confirms that $\mathrm{Asn}^{69}$ is responsible for chemotaxis.

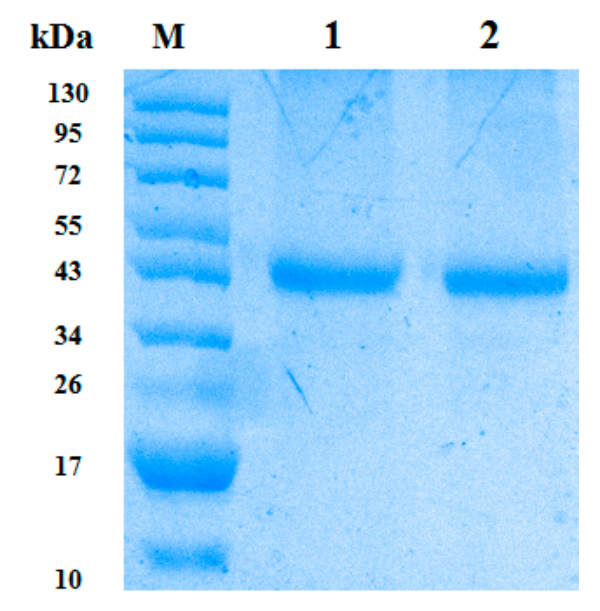

Figure 3. The expression and purification of GST-CypA. The CypA protein of yellow catfish was GST-fused expressed, purified and confirmed through SDS-PAGE, where the $\mathbf{M}$ represents the protein marker, Lane 1 represents $C y p A^{\mathrm{wt}}$ and Lane 2 represents $\mathrm{Cyp}^{\mathrm{mt}}$ in this figure.

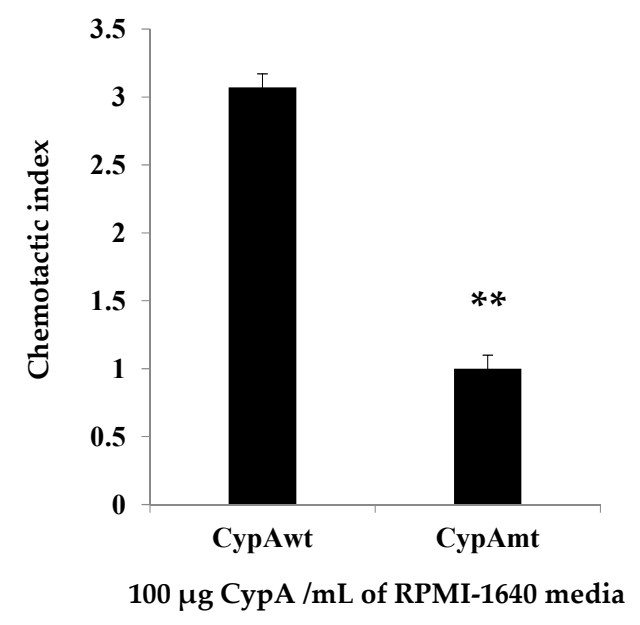

Figure 4. The chemotactic activity of recombinant CypA protein. The figure shows the comparative chemotactic activity of CypA ${ }^{\mathrm{wt}}$ (wild type) and CypA ${ }^{\mathrm{mt}}$ (mutant type) $(100 \mu \mathrm{g} / \mathrm{mL}$ ) of yellow catfish for head kidney leucocytes of yellow catfish. Data are expressed as the means $\pm \mathrm{SD},(n=3)$ of three fish. The bar with "***" is highly significantly different $(p<0.01)$.

\section{Discussion}

The body of knowledge about the role of fish skin mucus in host immunity compelled us to screen for its component characterization. Several studies demonstrated the presence of defensive proteins, including CypA, in the skin mucus of fish [10,12]. The skin mucus of yellow catfish has been recognized to have antimicrobial peptides, including pelteobagrin with strong anti-fungal and antibacterial activities [35]. Accordingly, in the present study, we have discovered interferon-induced GTP-binding protein $\mathrm{Mx1}$, vasa short form, $\beta$-enolase, recombination activating protein 1 , lsm12-like protein A and CypA from the skin mucus of yellow catfish by mass spectroscopy. These finding 
suggests that yellow catfish skin mucus is a strong defensive barrier against invading pathogens as CypA is associated in immune response against bacteria in yellow catfish [34], while enolase plays a role against cryptocaryoniasis [36]. Similarly, lsm12 is associated with translation regulation [37]; interferon-induced GTP-binding protein Mx1 has antiviral activity [38]; vasa play a key role in bovine spermatogenesis [39]; and recombination activating protein 1 has been considered as an immunological associate in fishes [40]. Our novel discovered proteins are addition to the previously reported immunological components, like immunoglobulins, agglutinins, lectins, lysins, lysozymes complement, carbonic anhydrase, crinotoxins, calmodulin, C-reactive protein, proteolytic enzymes and antimicrobial peptides in the fish skin mucus [41]. The number of proteins discovered in this study from the skin mucus of a healthy fish is less compared to those identified by others [42]. This interesting result suggests that fish can change the enzymes in the skin mucus according to environmental stimulus [43]. Nevertheless, together, these findings demonstrated the biochemically-rich nature of fish skin mucus.

CypA is ubiquitously expressed in all of the major tissues of teleost, including yellow catfish $[34,44,45]$. Accordingly, in the present study, we initially examined CypA by Western blot in the skin mucus of yellow catfish. Its expression detected by Western blot compelled us to examine its possible role in the skin mucus. Extracellular CypA can induce leucocyte migration in channel catfish and yellow catfish in in vitro examinations [33,34]. The fact that extracellular CypA attracts leucocytes in response to inflammatory stimuli is well documented [46,47]. In accordance with fish, the CypA was widely observed to encourage leucocyte migration in mammals [29,32,46-49]. In the present study, the secreted CypA in the skin mucus revealed strong chemotactic activity for yellow catfish leucocytes in a concentration-dependent manner. When CypA was blocked with anti-CypA antibodies inside the skin mucus, the chemotactic activity was decreased significantly compared to the negative control. This result suggests that the activity was solely due to CypA, as rabbit serum has no significant effect on chemotaxis. Our result hints that the fish secrete CypA in its mucus, which perhaps equips its epithelium by the infiltration of body leucocytes to fight against pathogens, because fish are permanently exposed to many pathogens, such as bacteria, viruses and parasites. To fight against these pathogens, fish uses the epidermis and its enzymatic secretion (mucus) [50], where it can change the clinical health parameters (e.g., enzymes) in the skin mucus according to environmental stimulus [43]. Moreover, the skin mucus of teleost fish is a strong chemoattractant for a variety of pathogenic bacteria $[1,50,51]$. Further studies could explore the precise molecular mechanisms involved in CypA chemotaxis and other possible roles in the skin mucus of fish.

Structurally, all CypA protein is composed of eight strands of antiparallel $\beta$-sheets in a flattened $\beta$-barrel with two helices capping the top and bottom. The residues Arg-55, Phe-60, Met-61, Gln-63, Phe-113, Trp-121, Leu-122 and His-126 constitute the PPIase active site. The residues Arg-55, Phe-60, Met-61, Gln-63, Gly-72, Ala-101, Asn-102, Ala-103, Gln-111, Phe-113, Trp-121, Leu-122 and His-126 constitute the CsA binding cite, while Arg-55 is the catalytic residue [52,53]. In mammalian CypA, $\mathrm{Arg}^{69}{ }^{6} \mathrm{His}^{70}$ and $\mathrm{Thr}^{107}$ are the critical residues responsible for leucocytes chemotaxis [54]. Hist ${ }^{70}$ and $\mathrm{Thr}^{107}$ are the conserved amino acids in the CypA of teleost (including yellow catfish). However, teleost fish CypA conserves Asn ${ }^{69}$ instead of $\mathrm{Arg}^{69}$. Whether the $\mathrm{Asn}^{69}$ residue is critical for chemotaxis in teleost CypA remains to be determined [33]. Therefore, we have proven that $\mathrm{Asn}^{69}$ is also the critical site responsible for chemotaxis in teleost CypA. As shown in the result, the chemotactic activity was significantly lowered (negligible) in CypA with the Asn ${ }^{69}$ mutant, compared to wild-type, indicating the precise residues for chemotaxis. This result provides an additional site $\left(\mathrm{Asn}^{69}\right)$ critical for leucocyte chemotaxis in teleost fishes. Our result also hints at the high homology among teleost and mammals, as $\mathrm{Arg}^{69}$ was declared as the responsible site for chemotaxis in mammalian CypA [54]. Specifically, this discovery provides a new target site in teleost CypA, which would help in the development of anti-inflammatory drugs without altering the rest of their natural functions.

In conclusion, our mucus-screened map reveals the presence of multiple defensive proteins and suggests them being involved in host defense. The chemotaxis of CypA for leucocytes in the skin mucus 
provides novel evidence and suggests their wide association in the teleost immune and pathogenic processes. Our finding that residues Asn ${ }^{69}$ of yellow catfish CypA is essential for chemotaxis will help in the development of novel anti-inflammatory therapies, specifically for the inhibition of chemotaxis activity without affecting the PPIase activity of CypA. Further molecular-based studies are needed to explore the additional function of extracellular CypA (especially in the mucus), in order to fight against the wide range of inflammatory diseases.

\section{Materials and Methods}

\subsection{Animals and Sample Collection}

Mucus samples were collected from healthy yellow catfish (100-150 g, 6 fish/group), which were acclimatized for two weeks before the experiment, according to the method described previously [1]. Fish were anesthetized, and the lateral surface of the skin was gently rubbed to avoid contact with the epithelium, using a soft rubber spatula. The skin mucus was either immediately subjected to transwell for chemotaxis determination or immediately homogenized in $50 \mathrm{mM}$ phosphate buffer solution (PBS), pH 6.0 containing $5 \mathrm{mM}$ EDTA on ice by using a glass homogenizer. The insoluble substances were removed by centrifuging at $15,000 \times g$ for $30 \mathrm{~min}$, and the supernatant was kept in a 1.5-mL sterile tube and stored in liquid nitrogen till further use. All experimental procedures involved in this study were permitted by the Institutional Animal Care and Institute of Huazhong Agricultural University (Ethical Approval No. HBAC20091138; Date: 15 November 2009).

\subsection{Mass Spectrometric Analysis}

Skin mucus was digested with sequencing-grade trypsin (Promega, Madison, WI, USA). MALDI-TOF MS and TOF/TOF tandem MS were performed on a MALDI-TOF-TOF mass spectrometer (4800 Proteomics Analyzer, Applied Biosystems, Foster City, CA, USA). Peptide mass fingerprints coupled with peptide fragmentation patterns were used to identify the protein in the International Protein Index (IPI) (http:/ / www.ebi.ac.uk/IPI/IPIhelp.html) [55] database (Version 3.67) using online MASCOT search engine (http://www.matrixscience.com) [56]. This mass spectroscopic method for protein identification was also used by others [57] (data mining was performed in 2013).

\subsection{Western Blot Analysis}

Western blot analysis was performed to check the expression of CypA in the mucus samples. Our laboratory has previously synthesized antibodies for yellow catfish CypA [34], which were used for Western blotting. In order to quantify the CypA, skin mucus was subjected to $12 \%$ SDS-PAGE tailed by membrane transfer. Membranes were blocked for nonspecific binding with Odyssey blocking buffer (Li-Cor Biosciences, Lincoln, NE, USA) for $1 \mathrm{~h}$ at room temperature followed by incubation with anti-yellow catfish CypA rabbit serum diluted in Odyssey blocking buffer $(1: 10,000)$ overnight at $4{ }^{\circ} \mathrm{C}$. Secondly, infrared dye-linked goat anti-rabbit IgG antibody $(1: 15,000)$ was added to the membranes and incubated at room temperature for $1 \mathrm{~h}$. The results were visualized and quantified using an Odyssey infrared imaging system (Li-Cor Biosciences).

\subsection{Sample Preparation, Plasmids Construction and Protein Expression}

Mammalian CypA has 3 critical sites responsible for chemotaxis $\left(\mathrm{His}^{70}, \mathrm{Thr}^{107}\right.$ and $\mathrm{Arg}^{69}$ ) [35]. Yellow catfish CypA conserves the 2 critical sites responsible for chemotaxis ( $\mathrm{His}^{70}$ and $\mathrm{Thr}^{107}$ ), but has $\mathrm{Asn}^{69}$ instead of $\mathrm{Arg}^{69}$. Whether Asn ${ }^{69}$ is also critical for chemotaxis needs scrutiny [33]. Therefore, the primers were designed (after the comparison of the yellow catfish CypA amino acid sequence with other vertebrates) for mutation in yellow catfish CypA and were based on that recommended site for chemotaxis determination (shown in Table 2). Total RNA was extracted from the liver of yellow catfish using RNAiso Plus (Takara, Dalian, China). For cDNA construction, the PrimeScript ${ }^{\mathrm{TM}}$ RT reagent kit with gDNA Eraser (Takara) was used following the manufacturer's instructions. The liver cDNA 
was further used as templates for PCR amplification with degenerated primers. The PCR products were detected by $1.0 \%$ agarose gel electrophoresis, and the amplified DNA fragments were purified and ligated into pMD18-T simple vector (Takara) and used for sequencing. After confirmation of the desired sequence, the fragment was ligated in the expression plasmid.

Table 2. Primers used for mutation in yellow catfish CypA. In both primers, the Asn amino acid is replaced by the Alan amino acid at position 69 , which produced the $\mathrm{CypA}^{\mathrm{mt}}$ protein. The codons for Alan (GCT and AGC) are presented bold in both forward and reverse primers.

\begin{tabular}{ccc}
\hline Primer's Name & Sequence $\left(5^{\prime}-\mathbf{3}^{\prime}\right)$ & Application \\
\hline 69: AAT-GCT (Forward) & GTGACTTCACAGCTCACAACG & cDNA amplification \\
69: AAT-GCT (Reverse) & GTGAGCTGTGAAGTCACCAC & cDNA amplification \\
\hline
\end{tabular}

The full length cDNA encoding yellow catfish-CypA was PCR amplified using the primers 5'-CTG GGATCC TAATGGCCAAACCCAGAGTGTT-3' and 5'-CAG CTCGAG TTAAAGTTGGCCACAGTCAG-3', in which BamH1 and XhoI restriction enzyme sites (bold and underlined) were added, respectively. After digestion with BamH1 and XhoI, the PCR product was ligated into the plasmid pGEX-5X-1, which produced proteins with the GST-tag. The recombinant plasmids CypA ${ }^{\mathrm{wt}}$ (wild-type) and CypA ${ }^{\mathrm{mt}}$ (Alan ${ }^{69}$-mutant) were transformed into Escherichia coli BL21 (DE3) competent cells (TransGen, Beijing, China), and the GST-fused CypA proteins were expressed. The induced recombinant proteins were purified using the Micro Protein PAGE Recovery kit (Sangon, Shanghai, China) following the manufacturer's instructions. The purified proteins were immediately checked for leucocyte migration in transwell plates (chemotaxis determination).

\subsection{Leukocytes Separation}

For the chemotaxis assay, leucocytes were isolated from the head kidneys of yellow catfish by the method described by Dong [34]. Briefly, fish were anesthetized with MS222 (Syndel, Nanaimo, BC, Canada); the head and body kidneys were aseptically removed and passed through a mesh $(100 \mathrm{~mm}$, Falcon) in RPMI-1640 containing 1\% fetal bovine serum (FBS) (Gibco, Grand Island, NY, USA) and $200 \mathrm{IU} / \mathrm{mL}$ penicillin plus streptomycin (Amresco, Solon, OH, USA). The resulting cell suspension was layered onto a 34\%/51\% Percoll (Pharmacia, Stockholm, Sweden) density gradient and centrifuged at $400 \times g$ for $30 \mathrm{~min}$ at $4{ }^{\circ} \mathrm{C}$. The interface was collected, and the cells were washed twice with RPMI-1640 at $400 \times \mathrm{g}$ for $10 \mathrm{~min}$ at $4{ }^{\circ} \mathrm{C}$ before being resuspended to $1.35 \times 10^{6}$ cells $/ \mathrm{mL}$ inRPMI- 1640 containing $1 \%$ FBS.

\subsection{Chemotaxis Assay of Skin Mucus}

To confirm the function of extracellular CypA present in the mucus, fresh skin mucus was checked for leucocytes migration. The transwell migration assay was used to measure the chemotactic activity of yellow catfish mucus that has an abundant amount of CypA. The transwell migration assay was performed with a 24-well costar transwell apparatus (Corning Costar Co., Cambridge, MA, USA). In the first phase, fresh mucus was diluted in RPMI- 1640 medium plus $1 \%$ FBS to $0.001 \%, 0.01 \%, 0.1 \%$, $1 \%$ and $10 \%(6.25,12.5,25,50$ and $100 \mu \mathrm{g} / \mathrm{mL})$, and $600-\mu \mathrm{L}$ aliquots of the dilutions were added to each lower chamber of the transwell units, except the control (blank). Subsequently, polycarbonate filters with a pore diameter of $8 \mu \mathrm{m}$ were placed onto the lower wells, and $100 \mu \mathrm{L}$ of target cells $\left(1.35 \times 10^{6}\right.$ cells $\left./ \mathrm{mL}\right)$ were added to the upper chamber. The unit was incubated on a shaker at $100 \mathrm{rpm}\left(25^{\circ} \mathrm{C}\right)$ for $90 \mathrm{~min}$. At last, the number of cells that migrated into the lower chamber was counted under microscope, and the result was expressed as a chemotactic index (the number of cells that migrated in response to mucus divided by the number of cells that migrated to the RPMI-1640 medium plus $1 \%$ FBS (blank control)). 
To check whether the chemotaxis is precisely due to CypA, we added antibodies in the second phase, and the above method and apparatus were used, except that anti-CypA anti-bodies were added (concentration 1:2000) to the lower chamber to block CypA inside the mucus, and the chemotactic activity was determined by the method as mentioned before. In this phase, the negative control group was also run, which contained rabbit serum plus mucus equal to the amount used in each group with antibodies.

\subsection{Chemotaxis Assay of CypA Recombinant Protein}

To explore and confirm the recommended residue responsible for leucocyte migration in yellow catfish CypA, we produced 2 types of protein $\left(\mathrm{CypA}^{\mathrm{wt}}\right.$ and $\left.\mathrm{CypA}^{\mathrm{mt}}\right)$ as mentioned before. For the evaluation of chemotaxis, the same method (mentioned above for mucus) and apparatus were used for CypA protein chemotaxis with the exception that the $\mathrm{CypA}^{\mathrm{wt}}$ and $\mathrm{CypA}^{\mathrm{mt}}$ protein were diluted in RPMI-1640 medium plus 1\% FBS to $100 \mu \mathrm{g} / \mathrm{mL}$, and $600-\mathrm{mL}$ aliquots of the dilutions were added to each lower chamber of the transwell units, except the control (blank). The number of cells that migrated into the lower chamber was counted under microscope, and the result was expressed as a chemotactic index (the number of cells that migrated in response to CypA ${ }^{\mathrm{wt}}$ and $\mathrm{CypA}^{\mathrm{mt}}$, divided by the number of cells that migrated to the RPMI-1640 medium plus 1\% FBS (blank control)).

\subsection{Statistics}

The data are presented as the mean \pm SD $(n=3)$. The data were analyzed using SPSS (20.0), and $p<0.05$ was considered statistically significant.

Supplementary Materials: Supplementary materials can be found at www.mdpi.com/1422-0067/17/9/1422/s1.

Acknowledgments: This work was jointly supported by the Natural Science Foundation of China (31572657, 31372563), the Fundamental Research Funds for the Central Universities (2014PY035, 2662015PY101) and the Special funds for science and technology from Hubei Province (2015BBA228, YSF2015000255).

Author Contributions: Farman Ullah Dawar, Jie Mei and Li Lin designed the experiments. Farman Ullah Dawar, Jiagang Tu, Jiangfeng Lan, Xing Xing Dong, Yang Xiong and Xiaoling Liu performed the experiments and analyzed the data. Farman Ullah Dawar, Muhammad Nasir Khan Khattak, Jie Mei and Li Lin finalized the manuscript writing.

Conflicts of Interest: The authors declare no conflict of interest.

\section{References}

1. Klesius, P.H.; Shoemaker, C.A.; Evans, J.J. Flavobacterium column are chemotaxis to channel catfish mucus. FEMS Microbiol. Lett. 2008, 288, 216-220. [CrossRef] [PubMed]

2. Vander Marel, M.; Caspari, N.; Neuhaus, H.; Meyer, W.; Enss, M.L.; Steinhagen, D. Changes in skin mucus of common carp, Cyprinus carpio L., after exposure to water with a high bacterial load. J. Fish Dis. 2010, 33, 431-439. [CrossRef] [PubMed]

3. Khong, H.K.; Kuah, M.K.; Jaya-Ram, A.; Shu-Chien, A.C. Prolactin receptor mRNA is upregulated in discus fish (Symphysodon aequifasciata) skin during parental phase. Comp. Biochem. Physiol. B 2009, 153, 18-28. [CrossRef] [PubMed]

4. Esteban, M.A. An overview of the immunological defences in fish skin. ISRN Immunol. 2012. [CrossRef]

5. Firth, K.J.; Johnson, S.C.; Ross, N.W. Characterization of proteases in the skin mucus of Atlantic salmon (Salmo salar) infected with the salmon louse (Lepeophtheirus salmonis) and in whole-body louse homogenate. J. Parasitol. 2000, 86, 1199-1205. [CrossRef]

6. Salles, C.; Gagliano, P.; Leitao, S.; Salles, J.; Guedes, H.L.M.; Cassano, V.P.F.; Giovanni, S.D. Identification and characterization of proteases from skin mucus of tambacu, a Neotropical hybrid fish. Fish Physiol. Biochem. 2007, 33, 173-179. [CrossRef]

7. Subramanian, S.; MacKinnon, S.L.; Ross, N.W. A comparative study on innate immune parameters in the epidermal mucus of various fish species. Comp. Biochem. Physiol. B 2007, 148, 256-263. [CrossRef] [PubMed] 
8. Cole, A.M.; Weis, P.; Diamond, G. Isolation and characterization of pleurocidin and antimicrobial peptide in the skin secretions of winter flounder. J. Biol. Chem. 1997, 272, 12008-12013. [CrossRef] [PubMed]

9. Nigam, A.K.; Kumari, U.; Mittal, S.; Mittal, A.K. Comparative analysis of innate immune parameters of the skin mucous secretions from certain freshwater teleosts inhabiting different ecological niches. Fish. Physiol. Biochem. 2012, 38, 1245-1256. [CrossRef] [PubMed]

10. Guardiola, F.A.; Cuesta, A.; Abellan, E.; Meseguer, J.; Esteban, M.A. Comparative analysis of the humoral immunity of skin mucus from several marine teleost fish. Fish Shellfish Immunol. 2014, 40, 24-31. [CrossRef] [PubMed]

11. Guardiola, F.A.; Cuesta, A.; Arizcun, M.; Meseguer, J.; Esteban, M.A. Comparative skin mucus and serum humoral defence mechanisms in the teleost gilthead seabream (Sparus aurata). Fish Shellfish Immunol. 2014, 36, 545-551. [CrossRef] [PubMed]

12. Rajan, B.; Fernandes, J.M.O.; Caipang, C.M.A.; Kiron, V.; Rombout, J.H.W.M.; Brinchmann, M.F. Proteome reference map of the skin mucus of Atlantic cod (Gadus morhua) revealing immune competent molecules. Fish Shellfish Immunol. 2011, 31, 224-231. [CrossRef] [PubMed]

13. Dawar, F.U.; Tu, J.; Khattak, M.N.K.; Mei, J.; Lin, L. Cyclophilin A: A Key Factor in Virus Replication and Potential Target for Anti-viral Therapy. Curr. Issues Mol. Biol. 2016, 21, 1-20. [PubMed]

14. Nigro, P.; Pompilio, G.; Capogrossi, M.C. Cyclophilin A: A key player for human disease. Cell Death Dis. 2013, 4, e888. [CrossRef] [PubMed]

15. Chen, S.; Zhang, M.; Ma, H.; Saiyin, H.; Shen, S.; Xi, J.; Wan, B.; Yu, L. Oligo-microarray analysis reveals the role of cyclophilin A in drug resistance. Cancer Chemother. Pharmacol. 2008, 61, 459-469. [CrossRef] [PubMed]

16. Montague, J.W.; Hughes, F.M.J.; Cidlowski, J.A. Native recombinant cyclophilins A, B, and C degrade DNA independently of peptidylprolyl cis-trans-isomerase activity. Potential roles of cyclophilins in apoptosis. J. Biol. Chem. 1997, 272, 6677-6684. [CrossRef] [PubMed]

17. Brazin, K.N.; Mallis, R.J.; Fulton, D.B.; Andreotti, A.H. Regulation of the tyrosine kinase Itk by the peptidyl-prolyl isomerase cyclophilin A. Proc. Natl. Acad. Sci. USA 2002, 99, 1899-1904. [CrossRef] [PubMed]

18. Jin, Z.G.; Melaragno, M.G.; Liao, D.F.; Yan, C.; Haendeler, J.; Suh, Y.A.; Lambeth, J.D.; Berk, B.C. Cyclophilin $\mathrm{A}$ is a secreted growth factor induced by oxidative stress. Circ. Res. 2000, 87, 789-796. [CrossRef] [PubMed]

19. Jin, Z.G.; Lungu, A.O.; Xie, L.; Wang, M.; Wong, C.; Berk, B.C. Cyclophilin A is a proinflammatory cytokine that activates endothelial cells. Arterioscler. Thromb. Vasc. Biol. 2004, 24, 1186-1191. [CrossRef] [PubMed]

20. Satoh, K.; Nigro, P.; Matoba, T.; O’Dell, M.R.; Cui, Z.; Shi, X.; Mohan, A.; Yan, C.; Abe, J.; Illig, K.A.; et al. Cyclophilin A enhances vascular oxidative stress and the development of angiotensin II-induced aortic aneurysms. Nat. Med. 2009, 15, 649-656. [CrossRef] [PubMed]

21. Liao, C.H.; Kuang, Y.Q.; Liu, H.L.; Zheng, Y.T.; Su, B. A novel fusion gene, TRIM5-cyclophilin A in the pig-tailed macaque determines its susceptibility to HIV-1 infection. Aids 2007, 21, S19-S26. [CrossRef] [PubMed]

22. Yeh, H.Y.; Klesius, P.H. Channel Catfish, Ictalurus punctatus, cyclophilin A and B cDNA characterization and expression analysis. Vet. Immunol. Immunopathol. 2008, 121, 370-377. [CrossRef] [PubMed]

23. Qiu, L.; Jiang, S.; Huang, J.; Wang, W.; Zhu, C.; Su, T. Molecular cloning and mRNA expression of cyclophilin A gene in black tiger shrimp (Penaeus monodon). Fish Shellfish Immunol. 2009, 26, 115-121. [CrossRef] [PubMed]

24. Song, X.; Wang, L.; Song, L.; Zhao, J.; Zhang, H.; Zheng, P.; Qiu, L.; Liu, X.; Wu, L. A cyclophilin A inducible expressed in gonad of zhikong scallop Chlamys farreri. Mol. Biol. Rep. 2009, 36, 1637-1645. [CrossRef] [PubMed]

25. Kern, G.; Kern, D.; Schimid, F.X.; Fischer, G. Reassessment of the putative chaperone function of prolyl cis/trans-isomerase. FEBS Lett. 1994, 348, 145-148. [CrossRef]

26. Seizer, P.; Ochmann, C.; Schonberger, T.; Zach, S.; Rose, M.; Borst, O.; Klingel, K.; Kandolf, R.; MacDonald, H.R.; Nowak, R.A.; et al. Disrupting the EMMPRIN (CD147)-cyclophilin A interaction reduces infarct size and preserves systolic function after myocardial ischemia and reperfusion. Arterioscler. Thromb. Vasc. Biol. 2011, 31, 1377-1386. [CrossRef] [PubMed]

27. Arora, K.; Gwinn, W.M.; Bower, M.A.; Watson, A.; Okwumabua, I.; MacDonald, H.R.; Bukrinsky, M.I.; Constant, S.L. Extracellular cyclophilins contribute to the regulation of inflammatory responses. J. Immunol. 2005, 175, 517-522. [CrossRef] [PubMed] 
28. Seizer, P.; Gawaz, M.; May, A.E. Cyclophilin A and EMMPRIN (CD147) in cardiovascular diseases. Cardiovasc. Res. 2014, 102, 17-23. [CrossRef] [PubMed]

29. Wang, C.; Rong, M.; Wang, L.; Ren, Z.; Chen, L.; Jia, J.; Li, X.; Wu, Z.; Chen, Z.; Zhu, P. CD147 up-regulates calcium-induced chemotaxis, adhesion ability and invasiveness of human neutrophils via a TRPM-7-mediated mechanism. Rheumatology 2014, 53, 2288-2296. [CrossRef] [PubMed]

30. Heine, S.J.; Olive, D.; Gao, J.L.; Murphy, P.M.; Bukrinsky, M.I.; Constant, S.L. Cyclophilin A cooperates with MIP-2 to augment neutrophil migration. J. Inflamm. Res. 2011, 4, 93-104. [PubMed]

31. Takanashi, S.; Nochi, T.; Abe, M.; Itaya, N.; Urakawa, M.; Sato, K.; Zhuang, T.; Umemura, S.; Hayashi, T.; Kiku, Y.; et al. Extracellular cyclophilin A possesses chemotaxic activity in cattle. Vet. Res. 2015, 46, 80. [CrossRef] [PubMed]

32. Guo, N.; Zhang, K.; Lv, M.; Miao, J.; Chen, Z.; Zhu, P. CD147 and CD98 complex-mediated homotypic aggregationattenuates the CypA-induced chemotactic effect on Jurkat T cells. Mol. Immunol. 2015, 63, 253-263. [CrossRef] [PubMed]

33. Yeh, H.Y.; Shoemaker, C.A.; Klesius, P.H. Chemotactic activity of channel catfish, Ictalurus punctatus (Rafinesque), recombinant cyclophilin A. J. Fish Dis. 2013, 36, 1041-1046. [CrossRef] [PubMed]

34. Dong, X.; Qin, Z.; Hu, X.; Lan, J.; Yuan, G.; Asim, M.; Zhou, Y.; Ai, T.; Mei, J.; Lin, L. Molecular cloning and functional characterization of cyclophilin A in yellow catfish (Pelteobagrus fulvidraco). Fish Shellfish Immunol. 2015, 45, 422-430. [CrossRef] [PubMed]

35. Su, Y. Isolation and identification of pelteobagrin, a novel antimicrobial peptide from the skin mucus of yellow catfish (Pelteobagrus fulvidraco). Comp. Biochem. Physiol. B 2011, 158, 149-154. [CrossRef] [PubMed]

36. Mai, Y.Z.; Li, Y.; Li, R.; Li, W.; Huang, X.; Mo, Z.; Li, A. Proteomic analysis of differentially expressed proteins in the marine fish parasitic ciliate Cryptocaryon irritans. Vet. Parasitol. 2015, 211, 1-11. [CrossRef] [PubMed]

37. Fleischer, T.C.; Weaver, C.M.; McAfee, K.J.; Jennings, J.L.; Link, A.J. Systematic identification and functional screens of uncharacterized proteins associated with eukaryotic ribosomal complexes. Genes. Dev. 2006, 20, 1294-1307. [CrossRef] [PubMed]

38. Pitossi, F.; Blank, A.; Schroder, A.; Schwarz, A.; Hussi, P.; Schwemmle, M.; Pavlovic, J.; Staeheli, P. A Functional GTP-Binding Motif Is Necessary for Antiviral Activity of Mx Proteins. J. Virol. 1993, 11, 6726-6732.

39. Luo, H.; Zhou, Y.; Li, Y.; Li, Q. Splice variants and promoter methylation status of the Bovine Vasa Homology (Bvh) gene may be involved in bull spermatogenesis. BMC Genet. 2013, 14, 58. [CrossRef] [PubMed]

40. Lee, J.W.; Kim, J.E.; Goo, I.B.; Hwang, J.; Im, J.H.; Choi, H.; Lee, J.H. Expression of Immune-Related Genes during Loach (Misgurnus anguillicaudatus) Embryonic and Early Larval Development. Dev. Reprod. 2015, 19, 181-187. [CrossRef] [PubMed]

41. Alexander, J.B.; Ingram, G.A. Noncellular nonspecific defence mechanisms of fish. Annu. Rev. Fish. Dis. 1992, 2, 249-279. [CrossRef]

42. Brinchmann, M.F. Immune relevant molecules identified in the skin mucus of fish using -omics technologies. Mol. BioSyst. 2016, 12, 2056-2063. [CrossRef] [PubMed]

43. Smith, A.C.; Ramos, F. Occult haemoglobin in fish skin mucus as an indicator of early stress. J. Fish Biol. 1976, 9, 537-541. [CrossRef]

44. Tu, H.B.; Yang, W.L.; Jiang, X.Y.; Chen, H.P.; Xiong, Q.; Wei, J.W.; Xu, A. Cloning, sequence analysis and evolutionary conservation of a full-length cDNA encoding cyclophilin A from red stingray (Dasyatis akajei). Fish Shellfish Immunol. 2003, 15, 359-366. [CrossRef]

45. Chen, L.; Mu, C.; Zhao, J.; Wang, C. Molecular cloning and characterization of two isoforms of cyclophilin A gene from Venerupis philippinarum. Fish Shellfish Immunol. 2011, 31, 1218-1223. [CrossRef] [PubMed]

46. Yurchenko, V.; Zybarth, G.; O'Connor, M.; Dai, W.W.; Franchin, G.; Hao, T.; Guo, H.; Hung, HC.; Toole, B.; Gallay, P.; et al. Active site residues of cyclophilin A are crucial for its signaling activity via CD147. J. Biol. Chem. 2002, 277, 22959-22965. [CrossRef] [PubMed]

47. Damsker, J.M.; Bukrinsky, M.I.; Constant, S.L. Preferential chemotaxis of activated human CD4 ${ }^{+}$T cells by extracellular cyclophilin A. J. Leukoc. Biol. 2007, 82, 613-618. [CrossRef] [PubMed]

48. Sherry, B.; Yarlett, N.; Strupp, A.; Cerami, A. Identification of cyclophilin as a proinflammatory secretory product of lipopolysaccharide-activated macrophages. Proc. Natl. Acad. Sci. USA 1992, 89, 3511-3515. [CrossRef] [PubMed] 
49. Allain, F.; Vanpouille, C.; Carpentier, M.; Slomianny, M.C.; Durieux, S.; Spik, G. Interaction with glycosaminoglycans is required for cyclophilin B to trigger integrin-mediated adhesion of peripheral blood T lymphocytes to extracellular matrix. Proc. Natl. Acad. Sci. USA 2002, 99, 2714-2719. [CrossRef] [PubMed]

50. Benhamed, S.; Guardiola, F.A.; Mars, M.; Esteban, M.Á. Pathogen bacteria adhesion to skin mucus of fishes. Vet. Microbiol. 2014, 171, 1-12. [CrossRef] [PubMed]

51. Larsen, M.H.; Larsen, J.L.; Olsen, J.E. Chemotaxis of Vibrio anguillarum to fish mucus: Role of the origin of the fish mucus, the fish species and the serogroup of the pathogen. FEMS. Microbiol. Ecol. 2001, 38, 77-80. [CrossRef]

52. Hur, S.; Bruice, T.C. The mechanism of cis-trans isomerization of prolyl peptides by cyclophilin. J. Am. Chem. Soc. 2002, 124, 7303-7313. [CrossRef] [PubMed]

53. Li, G.; Cui, Q. What is so special about Arg 55 in the catalysis of cyclophilin A? Insights from hybrid QM/MM simulations. J. Am. Chem. Soc. 2003, 125, 15028-15038. [CrossRef] [PubMed]

54. Song, F.; Zhang, X.; Ren, X.B.; Zhu, P.; Xu, J.; Wang, L.; Li, Y.F.; Zhong, N.; Ru, Q.; Zhang, D.W.; et al. Cyclophilin A (CyPA) induces chemotaxis independent of its peptidylprolyl cis-trans isomerase activity: Direct binding between CyPA and the ectodomain of CD147. J. Biol. Chem. 2011, 286, 8197-8203. [CrossRef] [PubMed]

55. International Protein Index (IPI). Available online: http://www.ebi.ac.uk/IPI/IPIhelp.html (accessed on 2 February 2013).

56. MASCOT Search Engine. Available online: http://www.matrixscience.com (accessed on 2 February 2013).

57. Li, G.; Chen, J.; Xie, P.; Jiang, Y.; Wu, L.; Zhang, X. Protein expression profiling in the zebrafish (Danio rerio) embryos exposed to the microcystin-LR ${ }^{\dagger}$. Proteomics 2011, 11, 2003-2018. [CrossRef] [PubMed]

(C) 2016 by the authors; licensee MDPI, Basel, Switzerland. This article is an open access article distributed under the terms and conditions of the Creative Commons Attribution (CC-BY) license (http:/ / creativecommons.org/licenses/by/4.0/). 